\title{
Unusual presentation of chlamydial peritonitis: case report
}

\author{
S DUFFY,* G CAWDELL, * AND N FIELDMAN† \\ From the Departments of *Obstetrics and Gynaecology and + Surgery, Central Middlesex Hospital, \\ London NW10 7NS
}

SUMMARY A 23 year old woman with peritonitis associated with Chlamydia trachomatis is described.

\section{Introduction}

The Fitz-Hugh-Curtis syndrome is perihepatitis due to genital tract infection. ${ }^{12}$. The classic presentation is of right hypochondrial pain mimicking cholecystitis. We describe a case of acute peritonitis with pain and tenderness in the left abdomen, which was due to infection with Chlamydia trachomatis.

\section{Case Report}

A white single mother aged 23 was admitted to hospital with a 12 hour history of left lumbar abdominal pain of sudden onset. She had had no recent gastrointestinal, urinary, or gynaecological symptoms. Two years previously she had been diagnosed on laparoscopy as having pelvic inflammatory disease. On examination her temperature was $37.8^{\circ} \mathrm{C}$, pulse 100 beats/minute and blood pressure $100 / 70 \mathrm{~mm} \mathrm{Hg}$. The left lumbar region of her abdomen showed appreciable peritonism and a fluid thrill on percussion. The adnexae were tender. Haemoglobin concentration was $14.6 \mathrm{~g} / \mathrm{dl}$ and white cell count $7.17 \times 10^{9} / \mathrm{l}$; serum amylase activity and liver function tests were normal as were erect and supine radiograms of the abdomen. The urine was clear on microscopy.

A diagnostic laparoscopy showed chronic pelvic inflammatory disease with a collection of serous fluid in the pouch of Douglas. There were typical "violin string" adhesions from the capsule of the liver to the overlying parietal peritoneum. The omentum was inflamed on the left at the level of the umbilicius. Subsequent laparotomy showed $250 \mathrm{ml}$ free fluid and inflammation of the jejunum and the proximal ileum and its mesentery, which contained multiple hard

Address for reprints: Dr G Cawdell, Lecturer, Department of Obstetrics and Gynaecology, University of Liverpool New Medical School, Liverpool L69 3BX

Accepted for publication 8 June 1984 lymph nodes. Injected threads of gelatinous white adhesions were present in the inflamed area. One of these was biopsied, and a peritoneal swab was cultured on modified Stuart's medium. A faint sickly sweet odour of rotten grass was noted.

Culture of bacteriological swabs from the rectum, urethra, vagina, and endocervix proved negative. Culture of endocervical and high vaginal swabs for chlamydiae transported to the laboratory in modified sucrose phosphate transport medium were also negative. Using the microimmunofluorescence technique, however, the titre of $\mathrm{IgG}$ antibody against $C$ trachomatis immunovars D-K was $1 / 4096$, which showed recent exposure to a potent antigenic stimulus. The gelatinous adhesions biopsied at operation showed vascular tissue with non-specific acute on chronic inflammation.

The patient's condition improved after treatment with oxytetracycline, metronidazole, and ampicillin. She was discharged home, quite well, after 11 days. The titre of chlamydial antibody (D-K) three weeks later was $1 / 510$. Her sexual partner refused investigation.

\section{Discussion}

The relation between right upper quadrant peritonitis, perihepatitis, and pelvic inflammatory disease was first described by Stajano in $1920 .^{3}$ The syndrome is commonly associated with the names of Curtis ${ }^{1}$, and Fitz-Hugh ${ }^{2}$ whose reports of the condition appeared in 1932 and 1934 respectively. Curtis described the association of "violin string" adhesions between the liver and the anterior abdominal wall, and Fitz-Hugh independently reported right upper quadrant pain as an early manifestation of the condition. The infecting organism in the Fitz-Hugh-Curtis syndrome was originally thought to be Neisseria gonorrhoeae, but more recently $C$ trachomatis has been strongly implicated. In our case the diagnosis of chlamydial 
infection was confirmed by very high titres of antichlamydial antibody. Such titres are diagnostic of acute infection. ${ }^{45}$

The presentation of the Fitz-Hugh-Curtis syndrome as right upper quadrant pain mimicking a surgical emergency is probably more common than is generally appreciated. Disease elsewhere in the abdomen producing severe symptoms and signs has not, however, been described previously. The findings on laparoscopy and laparotomy in our case were consistent with the classic features of the FitzHugh-Curtis syndrome, although it is unusual for the bowel wall and mesentery to be affected as well as the omentum.
We thank Mr H H Thomson, FRCS, FRCOG for allowing us to publish this case report.

\section{References}

1. Curtis AH. A cause of adhesions in the right upper quadrant. JAMA 1930;98:1221-2.

2. Fitz-Hugh T. Acute gonococcal peritonitis of the right upper quadrant in women. JAMA 1934; 102:2094-6.

3. Stajano C. La reacción frénica en ginecologia. Semana Medica Buenes Aires 1920; 27:243-8. (Cited in: Bolton JP, Darougar S. Perihepatitis. Br Med Bull 1983;39:159-62.)

4. Treharne JD, Ripa KT, Mårdh P-A, Sevensson L, Westrom L, Darougar S. Antibodies to Chlamydia trachomatis in acute salpingitis. British Journal of Venereal Diseases 1979; 55:26-9.

5. Muller-Schoop JW, Wang SP, Munzinger J, Schäpfer HU, Knoblauch M, Taummann RW. Chlamydia trachomatis as possible cause of peritonitis and perihepatitis in young women. Br Med J 1978; i: 1022-4. 